Max-Planck-Institut für demografische Forschung

Max Planck Institute for Demographic Research

Konrad-Zuse-Strasse 1 - D-18057 Rostock · GERMANY

Tel +49 (0) 3812081 - 0; Fax +49 (0) 3812081 - 202;

http://www.demogr.mpg.de

MPIDR WORKING PAPER WP 2007-006

FEBRUARY 2007

\title{
Meanings and attitudes attached to cohabitation in Poland \\ Qualitative analyses of the slow diffusion of cohabitation among the young generation
}

Monika Mynarska (mynarska@ demogr.mpg.de)

Laura Bernardi (bernardi@demogr.mpg.de)

(C) Copyright is held by the authors.

Working papers of the Max Planck Institute for Demographic Research receive only limited review. Views or opinions expressed in working papers are attributable to the authors and do not necessarily reflect those of the Institute. 


\title{
Meanings and Attitudes Attached to Cohabitation in Poland
}

Qualitative analyses of the slow diffusion of cohabitation among the young generation

An earlier version of this paper was presented at the Annual Meeting of Population Association of America, Los Angeles, March 30 - April 1, 2006

\author{
Monika Mynarska \\ Laura Bernardi \\ Max Planck Institute for Demographic Research \\ Konrad-Zuse-Str.1 \\ 18057 Rostock, Germany \\ Telephone: +493812081249 \\ Fax: +493812081549 \\ Contact: mynarska@demogr.mpg.de
}

\begin{abstract}
This study contributes to the understanding of the low level of non-marital cohabitations in Poland at the beginning of the XXI century. We employ interpretative analysis of semi-structured interviews in order to capture the meanings and attitudes associated to non-marital cohabitation by a selected sample of young Poles. Results indicate that although cohabitation has begun to be interpreted as a testing period leading to marriage, attitudes towards it are still very ambiguous. The idealization of marital commitment hinders the spread of informal unions. Understanding the determinants of the low cohabitation rate in Poland enable us to advance grounded hypotheses on its evolution in the near future and, more generally, to illustrate the ways in which local cultures influence the diffusion of behaviors.
\end{abstract}




\section{Introduction}

Since the 1970s, consensual unions have started to become an increasingly attractive option for young people in many European countries. Before that time, marriage was universal and took place at a relatively young age, and non-marital cohabitation ${ }^{1}$ was limited to marginal parts of society. Informal unions were a more likely form of cohabitation among people belonging to the lower strata of the society (Trost 1978, Villeneuve-Gokalp 1991), such as widows who did not want to loose their pensions (Nazio and Blossfeld 2003) or separated individuals who were not able to re-marry for legal or religious reasons (Haskey 2001). Only in a few cases, non-married cohabitants belonged to some avant-garde groups who were contrasting the establishment, whether identified with the Church or more general with social norms (Lesthaeghe 1995). Before the 1960s though, these groups had been marginal (Kiernan 2002). The picture has changed in recent years. More and more frequently, individuals enter cohabitation at early ages, and increasingly, they remain unmarried for the rest of their lives.

The spread of non-marital unions has occurred at a different pace across Europe (Carmichael 1995, Kiernan 2000, 2002, Nazio and Blossfeld 2003). In the Nordic countries, like Sweden and Denmark, consensual unions are currently as common as marital unions. In the Mediterranean region (Greece, Italy, Portugal, Spain), by contrast, the share of cohabitations is substantially lower. However, since in recent years consensual unions have grown in number at a faster rate than ever before in Southern Europe, there is an open discussion among demographers on whether we are likely to see the Nordic countries' model extending or not (e.g., see Rosina 2004, Rosina, Fraboni, 2004).

Even less clear is the evolution of cohabitation in Poland, a country that records one of the lowest levels of cohabitation in Europe. According to the National Census data, informal unions accounted for $1.3 \%$ of all cohabiting unions in 1988, 1.7\% in 1995 and still only 2.2\% in 2002 (Slany 2002). Not only are the absolute figures still very low, but also the doubling of the cohabitation rate in 14 years time is not remarkable if compared with the rapid diffusion of this type of union elsewhere. If we consider cohabitation in the 1960s in Sweden, we observe that in a comparable time period of 14 years, the share of informal unions climbed from $1 \%$ in 1960 to $12 \%$ in 1974 (Kwak 2005).

\footnotetext{
${ }^{1}$ From now on we will use the term cohabitation as synonymous for non-marital cohabitation (following Bacharch, Hindin, and Thomson 2000) as well as non-marital union and informal union
} 
A simple reading of these trends suggests that in Poland, couples who want to live together also want to marry beforehand, and they seem to adopt alternative living arrangements only very reluctantly. Why is it the case? This question calls for an investigation of the relatively unexplored domain of the cultural meaning of cohabitation and marriage in Poland. This paper breaks the path focusing on the meanings and the attitudes related to cohabitation among young Poles in the capital city of Warsaw. Meanings and attitudes associated to marriage and cohabitation are in constant dialogical tension and they can hardly be defined independently from each other. Most often marriage sets the frame of reference in which the concept of cohabitation is defined and judged against, whether as a prelude to marriage, as an incomplete or improper marriage, or as a form of union which is qualitatively and radically different from marriage. Caldwell (1982) wrote that in order to understand the nature of fertility decline it is imperative to also study those societies where fertility remained stable. Paraphrasing Caldwell we may say that we will never understand the onset of cohabitation increase until we understand the nature of the stable or persistent prevalence of marital unions. The interest of this paper goes beyond the explanation of the very low rate of cohabiting unions in Poland, since it contributes to the ever-evolving definition of the concept of "union".

\section{Cohabitation in Poland - what do we know?}

Official registers and national surveys offer only relatively little and scattered information on cohabitation behavior in Poland. Nevertheless it is worthwhile to give a brief overview of the little that is known about cohabitation of the adult Poles aged 15 years old or above who were cohabiting in 2002 (about 400000 individuals all together, CSO 2003) Generally, the picture which emerges is that:

- cohabitation in Poland is essentially an urban phenomenon: $75 \%$ of cohabiting couples live in cities (CSO 2003).

- cohabitation is not a popular living arrangement among young people: half of those living in informal unions are aged 40 or older and only $12 \%$ of them are younger than 25 (CSO 2003). In 1995, the share was 55\% and 10\%, respectively (Slany 2002).

- cohabitation is rarely chosen by those entering a first union: only $35 \%$ of the cohabiting couples are formed by never married partners (CSO 2003), while most are divorced, separated, or widowed.

- cohabitation is chosen mostly by individuals with a lower socio-economic status, with little education (Slany 2002) and with children: $57 \%$ of cohabiting couples had 
children in 1995 and $56 \%$ of them in 2002 . This is particularly noteworthy, given the relatively low level of extra-marital births in Poland (16\% of all births in 2004), and the strong influence of the Catholic Church (90\% of the population declares itself being Roman Catholics, CSO 2005).

Because cohabitation is associated with the above-mentioned individual characteristics, often cohabiters have enjoyed a relatively negative image in the society. Surprisingly, despite this negative image, non-marital cohabitation is far from being disapproved of if one considers the answers given to attitude surveys about couple living arrangements. On the contrary, approval has been growing with time in all age groups, and remarkably so particularly among younger people. This attitude dynamics is shown in Figure 1 to 3. The Figures report the results of the analysis of the approval gradient for two statements related to cohabitation presented to respondents in the Family and Changing Gender Roles Survey": the two statements are, a) "It is good when people who intend to get married live together for some time beforehand" and b) "A couple can cohabit even if they do not intend to get married". Figure 1 shows the approval gradient for the two statements in 1994 and 2002. These are the results for all respondents with valid answers, without age differentiation, but the increase is noticeable in all age groups.

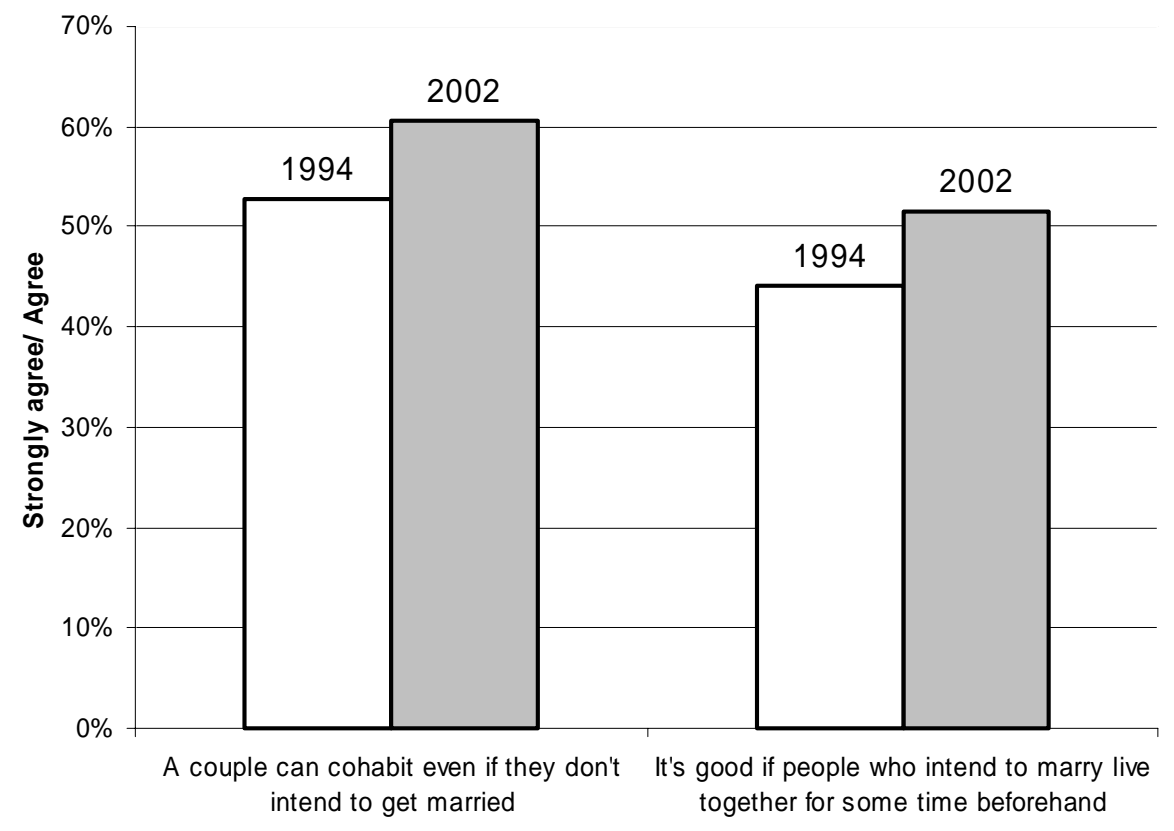

\footnotetext{
${ }^{2}$ The Family and Changing Gender Roles cross sectional survey was distributed in Poland twice, as part of the International Social Survey Program (ISSP) to a nationally representative sample of 1597 respondents older than 18 in 1994 and to 1252 ones in 2002. For details concerning the sampling see the questionnaire codebooks, ISSP 1994, 2002.
} 
Figure 1: Approval towards cohabitation: 1994 and 2002. ISSP 1994, 2002: own calculation.

Figures 2 and 3 illustrate the level of approval in 2002 by respondents' age. The disapproval of cohabitation is clearly the strongest among the respondents over 40 years old.

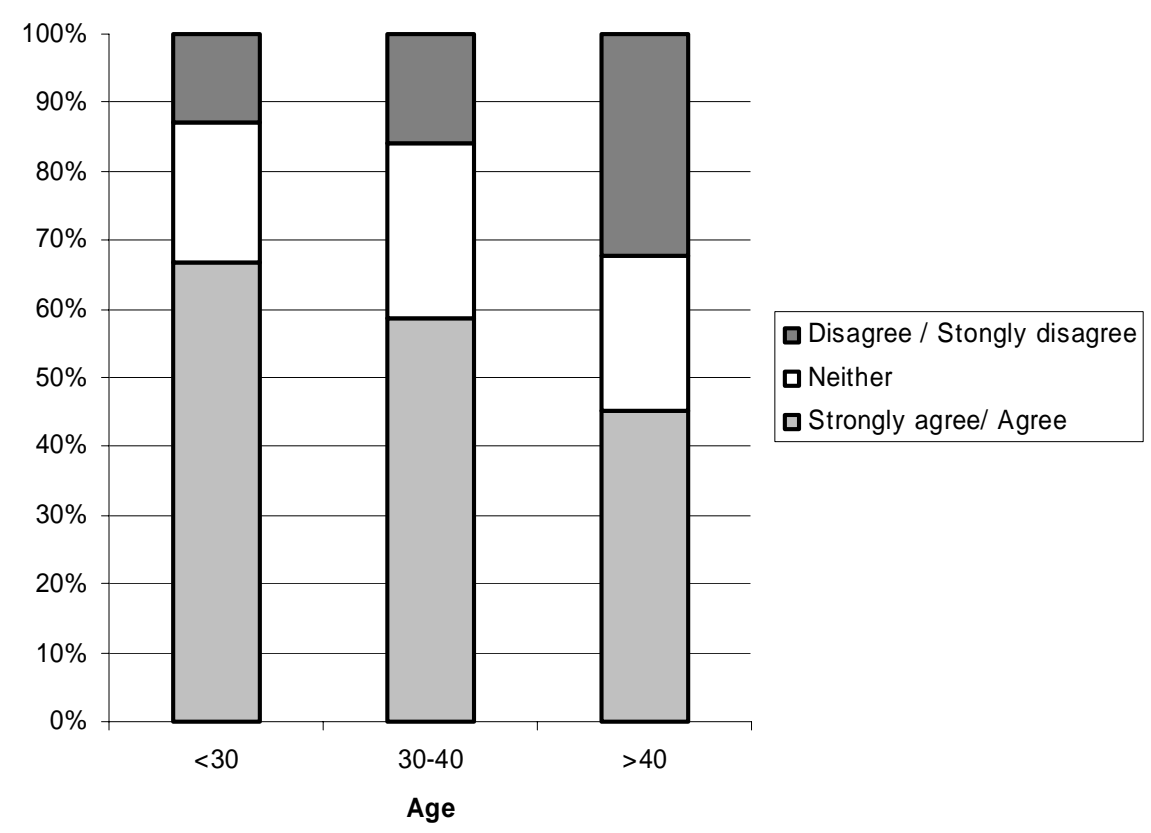

Figure 2: "It's good when people who intend to marry live together for some time beforehand": distribution of answers by respondents' age group. ISSP 2002: own calculation.

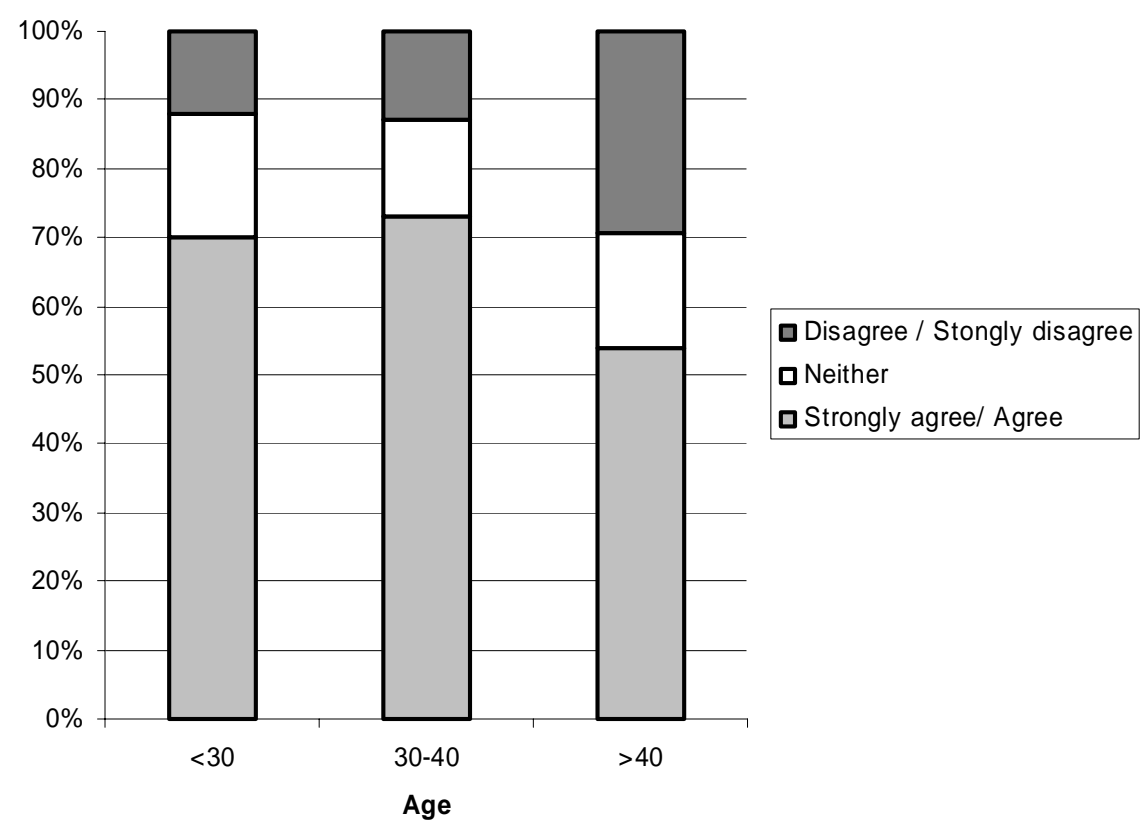

Figure 3: "A couple can cohabit even if they don't intend to get married": distribution of answers by respondents' age group. ISSP 2002: own calculation. 
The observation that young Poles are more liberal in their evaluation of cohabitation than their older compatriots is consistent with other research conducted in the region by Kwak (2005). In her 1999-2000 survey including several items concerning attitudes towards cohabitation, such as "Informal unions should exist", "I approve consensual unions", "I would like to live in an informal union", or "I would approve an informal union of my child", respondents younger than 40 agreed with these statements more frequently than those aged 40 or over.

The combination of positive attitudes and reluctant behavior we just described shows that young Poles are ambiguous regarding cohabitation. This ambiguity urges a deeper understanding of the meanings of cohabitation as a form of union. The questions to ask are: How is the significant change in attitudes among younger people related to the still very low prevalence of cohabitating behavior? And why is it, that precisely those who disapprove of cohabitation constitute the majority of the cohabiters group? The different attitudes of the younger and the older generations towards cohabitation is likely to be due to the different meanings or interpretative schema they attach to this type of living arrangement (see e.g. Manting, 1996)

In this paper, we focus on the former question; the meaning attributed to cohabitation and marriage by the younger generations. It is their behavior that is going to shape the union trends in Poland in the near future. In addition, the discrepancy between attitudes and behavior of the older generation seems more easily interpretable. Research on cohabitation in different contexts has shown that under specific conditions non-marital cohabitation, even when not explicitly approved, is practiced and tolerated as an alternative to marriage. Cohabitation in this case is an option for those whose first union ended with a death or a separation or for couples who are economically disadvantaged and cannot afford a proper wedding (Trost 1978, Villeneuve-Gokalp 1991, Kiernan 2002). All the above-mentioned conditions confer to cohabitation the character of a second best choice. If the older generation is close to this interpretation of cohabitation as second best and deviant, it is not surprising that cohabitation encounters little approval in principle. The higher approval of cohabitation by the younger generation though is at odds with this view. Research in other countries shows that cohabitation may be perceived as a testing period for marriage (Thornton 1989, Leridon and Villenueve-Gokalp 1989, Manting 1996, Kiernan 2002). It is increasingly treated as a strategy to get closer to a partner, but without having to give up on personal freedom and 
independence (Rindfuss and VandenHeuvel 1990, Clarkberg et al. 1995), or as a sign of liberal attitudes and rejection of the authority identified with parents and the Church (Villenueve-Gokalp 1991, Corijn and Manting 2000).

Unfortunately, there is currently no study on Poland that allows to empirically ground, let alone to test, the suggested hypotheses drawn from the literature referring to other countries' contexts. Existing survey data limits itself to record attitudes in a general form, but miss to clarify the rationale of the gap between attitudes towards a certain behavioral choice, its conditional evaluation in specific circumstances, or the multidimensionality of meanings that is potentially attributed to them. Even if the association between cohort of birth, behavior and meaning attributed to cohabitation would be proved to be similar in Poland as in other places, the puzzle for which cohabitation is least popular precisely among young people who approve it, would be unsolved. If young Poles were closer to the positive interpretations of cohabitation, why would they not also enter cohabitation more willingly, as their mates do elsewhere?

This paper aims at tackling this puzzle by presenting the findings from of a qualitative analysis of semi-structured interview data on cohabitation and marriage in Poland. We employ a content analysis approach, focusing on the way in which cohabitation is perceived and evaluated as well as to what extent it is considered an avoidable, a transitory or a desirable living arrangement by Polish young adults in their twenties and early thirties.

The paper is structured as follows: in the following section we explicit some theoretical considerations relating meanings and attitudes to behavioral diffusion in general and cohabitation behavior in particular. Section 4 describes the data and the methods and section 5 displays the range of meanings and attitudes associated to this form of living arrangement. A discussion of the findings in section 6 builds on this research case to argue for a comprehensive approach to demographic behavior whose continuity and change can be fully understood only if the meanings attributed to alternative life course choices are also understood.

\section{Cohabitation diffusion - theoretical considerations}

Cohabitation can be defined as "an intimate sexual union between two unmarried partners who share the same living quarter for a sustained period of time" (Bacharch, Hindin, 
Thomson 2000). The duration of the "sustained period of time" in which the couple share their living quarter and when this time starts and ends are important elements to define the kind of cohabitation at stake. The literature establishes meaningful distinctions between longterm and short-term cohabitation (Martin and Thery 2001) as well as premarital and postmarital cohabitations (Haskey 2001). Besides time, the reasons for cohabitation are also very strictly related to the interpretation of what choosing this living arrangement over marriage may mean, like alternative life style or a transitory living arrangement (Villeneuve-Gokalp 1991, Kwak 2005).

There seem to be some correlation between the prevalence of cohabiting behavior in a society and the prevalent meanings associated to it. Following Prinz (1995), Kiernan (2002) distinguishes four stages of cohabitation diffusion and the corresponding meaning associated to them. A first stage cohabitation is rare and either a deviant or an avant-garde behavior, performed by small, select groups. In a second stage, the number of cohabiting couples rises and extends to more socially heterogeneous groups. In this stage cohabitation is treated as a testing period which precedes marriage. In a third stage, a normalizing conception of cohabitation as an acceptable alternative to marriage spreads. Cohabitation in this stage still implies making a choice in contrast to marriage, and discrimination may exist between the two forms of union from a legal as well as a societal perspective. In the last stage cohabitation and marriage become indistinguishable.

The diffusion process increases its speed between the first and second stage. This is the moment at which cohabitation ceases being a deviant behavior, performed by a marginal part of the population. Cohabitation starts to gain a new meaning, especially for the young generation that treats it as the form of a "trial marriage". Kiernan (2002) terms this new phenomenon the 'nubile' cohabitation.

The spread of any innovative behavior in a society is linked to the diffusion of positive attitudes towards this behavior (Rogers 1995). Cohabitation becomes more popular when a change in its meaning is accompanied by a favorable change in the attitudes towards it. Ideational changes in societies which go in the direction of self orientation, individualism and denormativization are ideal conditions for attitudinal changes towards cohabitation as well as propulsions for its transition from one stage to the next (Lesthaeghe 1983, 1995, van de Kaa 1987, Lesthaeghe and Surkyn 1988). 
Following Kravdal (1999) we select four arguments which convincingly support this point. The first argument considers the quality of the relationship. The growing need for selfrealization may raise individual expectations about the quality of the relationship. Rather than entering marriage "blind", cohabitation is interpreted as providing the necessary testing phase needed to ensure a good match. The second argument builds on the fact that higher individualism and the need for independence reduce the attractiveness of a formal marital commitment. Here cohabitation becomes attractive because it provides the advantages of being single with those of being in a loving relationship. The third argument is similar: secularization negatively affects the attractiveness of marital unions because of the financial and public significance of the wedding ceremony. The fourth argument relates to the diminished salience of direct normative pressure. The ideational change leading towards individualistic and secularized societies and values implies the liberalization of norms and the distance from traditional pattern of union behavior. Cohabitation does not elicit or provoke social sanctioning.

Where does Polish society situate itself with respect to the four stages of cohabitation diffusion? Again, if using only the few sources available that we have presented in the previous section, the answer is hardly clear-cut. On the one hand, if we focus on the sociodemographic characteristics of the cohabitants in Poland and on the relative share of nonmarital unions, we should conclude that Poland is fully in the first stage of the cohabitation diffusion and with no visible indications of an imminent transition to the next stage. On the other hand, attitudes toward cohabitation become more favorable in the younger part of the population. We speculated that these differences may be interpreted with the diffusion of different meanings attached to non-marital unions, an ideational change which would situate Poland at least in the second stage of cohabitation diffusion. However, rather than the rapid increasing rate of cohabitation that we observe in the Southern European countries, in Poland marital unions do not yet loose terrain. The ambiguous contingency represented by the current state of cohabitation in Poland entails two alternative consequences in terms of expectations about future trends. One possibility is that the four-stage frame is valid universally and applies also to Poland, so that it is just a matter of time until the currently registered approval of cohabitation translates in the predicted boom of non-marital unions. The alternative possibility is that there are local specificities in the Polish social and cultural institutions which combine a rising approval of the new form of union together with a strong preference for marital unions. 
From both perspectives, it is worth investigating the meanings and attitudes towards nonmarital unions and marriage. Such investigation is well timed since, if the cohabitation boom predicted by the four-stage theoretical frame indeed occurs, we are in the position to study perceptions and meanings at the origin of a long-term process. This origin is a period in which inconsistencies start to emerge between well-known union practices and positive attitudes towards new forms of union. This ambiguous time is possibly the best to do research on what eventually triggers a behavioral shift, provided that contradictions are visible and questioned. However, even in the case in which the prevalence of cohabitation will not increase as predicted by the four stage frame, we have good reasons to want to examine from close-up what makes Poland different from other contexts. If the four stage frame universalistic claims are disproved by facts in the near future, then we are in the position to define a different pattern of cohabitation diffusion, or rather of its stalling. Our approach in this paper is to focus on the subjective definition of attitudes and meanings, while postponing to further research an examination of the elements in the social structure and the social organization which may interact with the individual level analysis (Fricke 1997).

\section{Methodological approach and sampling}

Since the central interest of this paper is to examine the meanings related to a specific behavioral choice, a suitable approach is to use explorative approaches of data collection and analysis (Maxwell 1996). In this specific case we are dealing with a behavioral choice that is likely to involve multidimensional aspects, like it is the case of living arrangements. The choice of type of union is a clear example of complex choice in which economics, legal, social and religious dimensions intervene in different manners to produce the final outcome. The need to approach such a complex choice via qualitative research has been already expressed by demographers (Carmichael 1995), and stressed with emphasis in Poland where it is a relatively unexplored field so far (Slany 2002).

We conducted problem-centred interviews (Witzel 2000) which combine methodological openness in the data collection with a specific theoretical focus on one or more topics. Our guideline covers six topical areas providing rich information both on the history of the respondents and on his or her current situation. In particular the interview includes (1) a retrospective biographical narrative of the respondent up to the moment of the interview and 
his or her current life situation, (2) the union history and the status of the current relationship, (3) the fertility history and the current desires and intentions related to childbearing and parenthood, (4) the experiences of or value-orientations connected to being a parent, (5) the impact of the political and economical transformation of the early 1990s on respondent's family and fertility plans, (6) plans and fears related to the future life course development. The analysis for this paper mainly draws on the information gathered on union history and current status and on plans and fears for the future development of the life course. These sections of the interview cover questions about the respondent's attitudes towards cohabitation and marriage, both in terms of his or her experiences with and of intentions related to it. However, the analysis concerns the whole interview, both because the open nature of the interview allows respondents to bring up the same topic in different moments in the course of the conversation, and to be able to contextualize the meaning attributed to cohabitation within the respondent's interpretative frame of references.

We interviewed 48 individuals ( 26 women and 22 men) at various stages of their family careers: couples still dating, cohabiting or married, childless or with one child. For most couples it was possible to interview both partners. Women's ages ranged from 20 to 30 and men's 20 to 35 . Because the aim of the study was to capture the innovative aspects of cohabitation in Poland, the nubile form of cohabitation, the sample is limited to the group of people most likely to adopt modern attitudes and behaviors. In particular, we interviewed people living in Warsaw, who are exposed to the modern and cosmopolitan climate of a capital city. The respondents are also better educated than the overall population, as only two educational subgroups were defined: up to high school exams (mostly secondary education), or higher (studying, Bachelor's or Master's Degree). The above characteristics are typical for "early knowers of innovations" (Rogers 1995, pp. 166-7), who are a starting point for the diffusion of any new attitudes and behaviors. Our sample can be certainly regarded as a group more likely to adopt modern behaviors: among those currently married, the majority has experienced cohabitation (17 out of 26). The duration of living together with a partner without being married varied from 1 to 3 years. The sample of 48 interviews is described in detail in Appendix 1. While our sample is not representative of the population of young people in Poland, we are confident that the care we put into trying to diversify its composition guarantees that the content of the collected interviews is a good representation of the range of meanings associated to cohabitation in the age group and the level of education considered. To assure good representation, we conducted interviews with people in various life situations, 
with different backgrounds and relationship histories. During the fieldwork the sample was extended, as the collected material had indicated that couples, who cohabit and significantly postpone their marriage, may add new content to our analyses. By adding more cases, we reached the moment of theoretical saturation (Flick, 2002): new interviews were bringing no or little new knowledge about the topic under investigation and no new meanings of cohabitation appeared.

\section{Analysis and findings}

The analysis of interviews is modeled by the "grounded theory" approach (Strauss and Corbin 1998). During an interview, respondents talk about their experiences, observations, and opinions connected to cohabitation and marriage. Ideal or experienced forms of living arrangements are richly described and evaluated through associations, metaphors and clarifications which allows the analyst to define and categorize different aspects related to each of the living arrangements, like ways of entering it, its social significance, changes in partners' life and its impact on relationship, to mention just a few. In the following step we search for patterns and regularities in the categories built, by constant comparison and contrasting them within and between interview cases. These patterns identify the main concepts which relate to cohabitation and marriage in the data (Charmaz 2000). The last step is to recognize the relations between the different concepts and theorize about the meaning of the different forms of living arrangements, their similarities and dissimilarities (Strauss and Corbin 1998, Flick 2002). Figure 4 depicts the network of concepts related to cohabitation and marriage as reconstructed from the interviews in the study.

Cohabitation spreads when people perceive that its advantages overtake its disadvantages, they develop a positive attitude towards it and they evaluate it as an attractive option among other possible behaviors (Rogers 1995). Thus, drawing a complete picture of the meanings of and attitudes towards cohabitation requires considering it together with other available forms of relationships - especially marriage, which is still universal in Poland. However, in this paper we present only a partial view of the meaning related to marriage, that is those aspects of marriage which are specifically paralleled or contrasted with consensual unions. These are by no means all the opinions related to marital unions. 


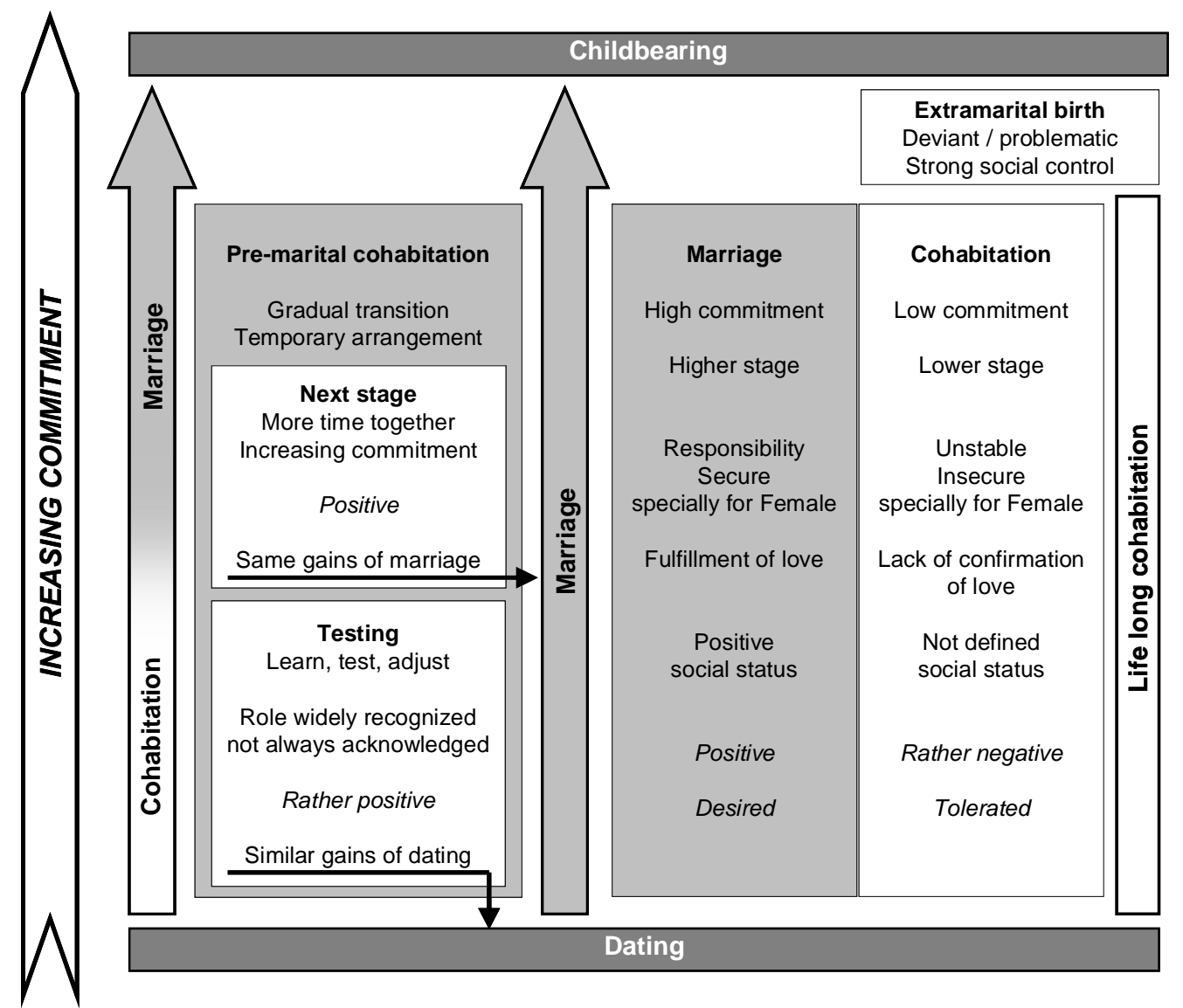

Figure 4: Network of concepts related to cohabitation and marriage. Three paths of relationship development: premarital cohabitation - marriage; direct marriage, continuous cohabitation - meanings and evaluation of concepts.

Figure 4 captures the images of cohabitation and marriage presented by men and women at the various stages of their relationship development. The core differences in meanings and attitudes, which can be attributed to the different characteristics, backgrounds and experiences of our respondents, will be indicated. These differences, however, do not change the overall picture, although they are certainly an interesting topic for further investigation.

Before entering into details to illustrate the elements composing Figure 4, it is worthwhile noting that there are mainly just two meanings associated with cohabitation, which are evaluated to some extent positively and both see cohabitation strictly as a premarital living arrangement (left column in Figure 4). The first meaning perceives cohabitation as the natural step in relationship development and emphasizes how living together before marrying is connected to an increasing commitment and the possibility to spend more time with a partner. The second perception interprets cohabitation as a testing period for marriage, and also in this view it is an interim step in the family formation process. Cohabitation is seen as a temporary arrangement, followed by marriage and childbearing. 
The respondents do not regard cohabitation as a possible alternative to marriage. If they talk about life long cohabitation, they do so contrasting it with living in wedlock and they contrast these living arrangements in many respects (right column in Figure 4). The strongest position expresses a permanent non-marital cohabitation solution as a "dead end": it does not (or should not) lead to childbearing and it indicates that the commitment of partners is not increasing.

Both when talking about marriage and about cohabitation the concept of commitment seems to be the key concept for our respondents: cohabitation acquires a positive evaluation only as it enhances the commitment that married partners eventually express and officially at the moment of marrying

The results, presented in sections 5.1 - 5.4, are structured accordingly to the above map of concepts. First, we present meanings and attitudes connected to cohabitation as a premarital living arrangement. We make a clear distinction between meanings of and attitudes towards cohabitation, presenting them separately. Meanings are understood as interpretations that people have about the aims and roles of behavior (Maines 2000, Schwandt 2000). Attitudes in turn always include an element of evaluation; they are relatively enduring tendencies to perceive things positively or negatively (Ajzen and Fishbein 1980, Thurstone 1931). Second, we describe how cohabitation is contrasted with marital union. We conclude, showing that cohabitation is approved only as a temporal solution and marriage is an only desirable way of living.

\subsection{The meanings of cohabitation}

We present the two main meanings associated to premarital cohabitation by the young Poles we interviewed: cohabitation as a trial period, and as a next step in the relationship development.

\section{Testing}

It is widely recognized that cohabitation gives partners the opportunity to learn, test, check, and possibly adjust to each other before the decision to marry is made. This role of living 
together without marriage is acknowledged by the respondents still dating, cohabiting and married after previous cohabitation, but less clearly by those married directly.

In the interviews, we frequently find expressions describing cohabitation as the stage of relationship at which partners "learn about their advantages and disadvantages". It is the time at which "you can get to know each other largely and avoid some conflicts later on". The avoiding is possible because during this period people adjust to each other, they "learn how to treat each other and other person's habits". Frequently, "avoiding conflicts" means separation.

"Only if you live together, you can get to know this person truly, and see, whether he or she is the right one for the next stage of your life. Or for the rest of your life" (Female, cohabiting).

"People get to know each other and learn about their shortcomings pretty quickly. And then they can either stay together or split" (Male, married directly).

Still, separation at this stage of the relationship development is not perceived negatively. Our respondents explain:

"The sooner you notice these negative things - the things that trouble you the mostthe better. It is better to split up earlier rather than when you have a family already" (Female, in a relationship, but living apart).

However, the opinion that cohabitation is a good test for a couple is not shared universally. Some respondents acknowledge the trial role of living together prior to marrying, but they believe this is not the only way to test and adjust. In their opinion, people can get to know each other well already while dating; they do so by spending a lot of time together, talking, and being honest with each other. Thus, consensual union is treated as an option "for those couples that don't see each other very often".

In a few cases including those who did cohabit, they deny the probationary role of premarital living together giving various reasons. For instance, they claim that "people get to know each other during their whole life" or that only "marriage is a real test itself". One respondent, the woman married after premarital cohabitation says, "Perhaps you should begin not from the test but from finding the second half". That would indicate that testing should take place 
before a couple decides to live together. One male respondent, also married after previous cohabitation, puts it explicitly, when talking about the decision to move in together with his partner,

"We knew already then, because it was 7 years of our relationship, we knew that it is not going to change our relationship (...) we knew each other pretty well and we knew what we want and what we are after".

If cohabitation is not perceived as a test, what role does it have? Another male respondent explains it clearly, "We didn't treat this as any kind of test; we simply very strongly wanted to [be together]".

\section{The next step in the relationship}

Some respondents perceive the act of moving in together simply as entering the next, higher level of a relationship. They present it as "the natural consequence of two people being together". They see it as a normal way of relationship development, "first staying over night, spending more time together, doing some everyday things together more and more often" until the moment is reached at which it becomes "difficult to part from each other" and the couple moves in together for good. We come across these views among those who experienced premarital cohabitation, as well as those still living apart at the time of the interview.

Treating cohabitation as the next stage in the relationship development is also reflected in the process, in which the decision for this living arrangement is made. Or rather, we should say "is not made" because for most of the couples the transition to cohabitation is a long and gradual process. Two quotes from the interviews illustrate this best:

"He was staying at my place for some time, sometimes it was all mixed up and he was staying for so long that I didn't really know whether he was living in with me or not" (Female, married after cohabitation).

"I really can't say when it actually happened when we had started to live together (...) we were slowly bringing over our stuff. Firstly, we stayed there for just a few days, then we spent a whole weekend in this flat and for the rest of the week we used to go 
back to our places, and later on we stayed there permanently" (Male, married after cohabitation).

This long-lasting transition period is a prevailing model among the interviewees who have ever experienced cohabitation. We notice also among the couples still living apart at the time of the interview that this process is ongoing. Some of the respondents even consider themselves cohabiting, although they spend only a few days during the week in one apartment and one of the partners officially lives with his or her family of origin.

The decision to move in together takes the form of "a big step", mostly for some external reasons, e.g., it arises from an opportunity to cheaply rent or buy a flat, a decision to work abroad together for some time, a necessity to leave one's parental home or it arises from a pregnancy.

The notion of cohabitation as a trial period or as a natural step in the relationship development varies among the respondents. For some of them, cohabitation means mostly testing. The others emphasize the aspect of relationship development and argue against the testing role. Yet commonly, the experience of consensual union is a mixture of both: getting closer and probing each other. Let us now present how this living arrangement is evaluated.

\subsection{The attitudes towards cohabitation}

The attitudes towards premarital cohabitation are ambiguous as we had anticipated. On the one hand, respondents say that "it's worth to live together before marriage", "it is good" and it makes for "a super experience". On the other hand, some of the seemingly favorable opinions are expressed in a peculiar way. The respondents talk about premarital cohabitation as "nothing bad", or something they would "not forbid" their children to do (but they would not encourage them to do it). Some respondents are "not completely sure that this is good". Premarital living together is perceived as advantageous, but not universally, and it "depends on the couple" whether it is a beneficial choice or not. One of the interviewees says, "I suspect that only in 30\% of the cases this is a right decision" (Male, married directly, but cohabiting before with another partner). 
It is also clear that the respondents evaluate this living arrangement differently, depending on the meaning they attach to it.

The attitudes towards cohabitation, perceived as a trial period before marriage, are not unanimous. Most of the respondents, who recognize this meaning, evaluate it positively, saying that "it is important to check first" and that "one needs to know each other and it's good to live together for some time." Some find this probationary stage necessary and believe that "being together and getting married and only then moving in together is nonsense". The lack of a trial period may impact the stability of the future marriage. One of the respondents says,

“It seems to me that these divorces result from the fact that people didn't really know each other. Well, there are sporadic cases that people know each other, live with each other and later [it works out]... No, it doesn't seem to me. I don't imagine it without living together first" (Male, cohabiting).

From this perspective, premarital cohabitation is advantageous, because it improves the future relationship and lowers the risk of divorce. However, some respondents, mainly those who married directly, mention the negative aspects of this meaning of premarital cohabitation.

"This learning before the wedding leads to the situation when after the wedding it looks like an old marriage. There is no fascination, no surprising each other any more" (Female, married directly).

The other reason, for which the probationary period is sometimes evaluated ambivalently, is because it may be interpreted as a sign that partners do not love each other strongly enough to marry. The story of one of the respondents is a perfect exemplification here.

"With my ex-girlfriend, we were supposed to marry and I left her two months before the wedding. We had lived together for 11 months and (...) checked whether we had wanted this, whether it had been fine for us. But with B. [current wife] I didn't have any kind of objections". And so they married directly.

When the respondents treat moving in together as a natural step in the development of their relationship, their evaluation of this stage is more unequivocal. Here, the main advantage of cohabitation relates to the fact that a couple can spend more time together. Our interviewees talk about these aspects enthusiastically, 
"It was generally something wonderful, very beautiful feeling, and that we were always together. In the beginning it was so cool that basically we did nothing separately. Everything, anything, even stupid vacuuming, we were holding the vacuum cleaner together. So it was very romantic” (Female, married after cohabitation).

"And even when I finish late she will be home earlier and waiting there for me. Super, just great (...) the joy is that even when we are very busy or something, she will cuddle up into me with her back and we will be together. And that's what it's all about" (Male, married after cohabitation).

However, although these features make cohabitation appealing, the same positive emotions and feelings are connected to living together after marriage. It is not the consensual union itself that is attractive, but the fact of sharing living space and being closer to each other.

"There are pros and cons to any arrangement" but even the respondents, who are skeptical about the advantages of living together before marriage, speak generally in favor of such a choice, or they remain neutral in their evaluation. To our surprise, such neutral opinions are expressed also by the respondents who experienced cohabitation. Although for some reasons, men dominate in this group. A few respondents speaking definitely against premarital cohabitation can be found among those who married directly, but these cases are rare.

The situation changes rapidly when we ask the interviewees to consider the issue of remaining in consensual union instead of getting married. In this case, men and women, regardless of their marital status and personal background, almost universally express the same opinions. They do not criticize or condemn such behavior openly. They accept it, tolerate it, but it is apparent from the interviews that this is not the choice they would dream of for themselves. On the one hand, they say that this is "everybody's personal issue" and that they "would not criticize people living together or even having a child" out of wedlock. On the other hand, they "can't imagine living like that in the long run." They want to "develop, move on" and turn their lives to "the next right path", which is marriage.

Marriage is evaluated positively as "a sign of real love" and "fulfillment of the feeling of love". One of the respondents puts it explicitly, "If we talk about real love, we talk about marriage". The word "real", in fact, is used frequently when this form of union is concerned. 
"Only after marriage can one talk about a real couple" - marriage constitutes the moment of "forming the real family." Does this indicate that everything before marriage was not real?

When the interviewees speak about cohabitation as an alternative to marriage, they happen to use clearly negative expressions, which was not the case for premarital living together. One respondent, a woman who experienced premarital cohabitation, gives an example of a couple who has "lived together for six years and they are still not married", and she concludes, "He simply doesn't respect the woman". The interviewees use disrespectful labels for these sorts of unions. They use words like "concubine" or "concubinage" and they sometimes spontaneously add a comment like, "They speak about 'concubinage' in police announcements and it sounds dreadful", "a concubine is an ugly word”. The Polish idiom "to live at a cat's paw" ("żyć na kocią łapę") is used by some of the interviewees. This expression is very pejorative, similarly to another Polish expression, "to live together with a cycling license” (“żyć na kartę rowerową”). These idioms describe consensual unions as insecure and not serious.

All in all, cohabitation as an alterative to marriage is acceptable but not desired. One of the respondents asks a rhetorical question,

"Would you like to be with somebody without getting married? I guess you could. You could, but you don't feel that bond then" (Male, married directly).

Why do young people want to marry? Why is cohabitation not an attractive alternative? The above quote already suggests one of the reasons, but in order to understand this better, we will present the main differences between these two living arrangements, as perceived by the respondents.

\subsection{Cohabitation vs. marriage}

To the interviewees, living together as a married couple, or not, is a very different kind of union. There are four main dimensions along which the comparison between these forms of union is made: commitment, religion, social appreciation and childbearing. 


\section{Commitment}

The level of commitment, responsibility and stability contrasts formal and informal unions most strongly for all respondents. Cohabitation is perceived as something unstable and insecure. This is the stage at which people are likely to break up "because they have an open gate and they can walk out at any time". They have "no commitments and can separate easily" and this kind of union "falls apart faster" compared to marriage. As one of the respondents explains,

"This relationship, which is not sealed with this paper, is not stable. Because one of the parents could get the impression that he or she is free and not a member of the family. And if any problems arise, it would be easier to blow the relationship out from the inside" (Male, married after cohabitation).

On the other end, marriage is perceived as "commitment", "obligation" and as "having new, shared responsibilities". The respondents elaborate on these aspects frequently. The following quotes are representative of the perceived commitment in marriage, in contrast to the quotes on cohabitation:

"Marriage is cementing [the relationship] additionally, it is as simple as that. This stupid paper is difficult to break. I don't know. These are my impressions, my feelings. It keeps me in a bit" (Female, married after cohabitation).

"It only cements it or it shows that these people love each other and they show it with the wedding” (Male, in LAT relationship).

Commitment and binding are clearly desirable for our respondents, because "when one decides for the relationship, it is not to leave any kind of gates open”.

Some male and female interviewees recognize that this issue is more important for women. For men, "generally, statistically it is of lower significance". For women, getting married means "security" and it is a way in which a man can assure his partner about his love, a way to,

"Make herfeel more certain, make her know that [he] supports her and loves her. It's yet another certification of love, a certification that we want to be, that we are together and we will be together" (Male, married after cohabitation). 
The binding role of marriage is connected to the issue of marital vows, made "in front of people, in front of God, in Church". That brings in another difference between the living arrangements discussed.

\section{Religion - The Catholic Church}

Poland is a Catholic country. The Catholic Church regards heterosexual marriage as the only legitimate kind of union. Cohabitation is not approved because it implies premarital sex, which is considered a sin. Most of my respondents declare to be Catholics and emphasize the importance of a church wedding and marital vows. At the same time, all of them have experienced premarital sex and only in case of two female respondents did this fact result in any kind of moral dilemmas when considering cohabitation. A strong statement like, "I felt dirty" is found only in one interview. In most cases, this issue is not even mentioned. It seems that the interviewees decide in favor of a Church wedding for reasons other than religiosity.

Firstly, they want to enter the marital bond for reasons of having a traditional setting. One of the female respondents says,

"I'm a very romantic person and I always knew that I wanted to have this setting, this white dress, this vow. It's perhaps the only party in the whole life when you have your closest family and friends together (...) the most beautiful day in my life” (Female, married after cohabitation).

Some respondents admit explicitly, "We had the Church wedding purely and simply because this setting is really beautiful".

For our second point we come back to the issue of commitment. Marital vows pay a significant role here. One of the respondents says,

“In my opinion, Church marriage is more binding than the state one. I don't know why, but I think that's the way it is. The state marriage... I can go, pay for the divorce and I'm free and that's it. But there is no divorce in Church. And that's why it is more binding" (Female, cohabiting).

There are many examples of similar opinions, shared by the respondents of different backgrounds, 
“This wedding seems to me even more important, that it gives such, I don't know, this vow would be for me...I would feel more secure, a kind of safer" (Female, in LAT relationship).

“When you take only a state marriage and if something didn't spark there, something didn't match that we can't get along, and then you just take a divorce, quick and easy. And the church wedding is a kind of commitment" (Male, married directly)

The Church wedding is held by my respondents to be a beautiful ritual in which they are tied securely to each other. From this perspective, the key aspect that differentiates marriage and cohabitation is, in fact, again: commitment.

\section{Social perception}

Another meaningful distinction between formal and informal unions is made by the way in which they are perceived in society. Note that the Polish language has no proper expression to describe people living in an informal union. We have already mentioned some pejorative labels, and the alternatives to them are few. The word "partner" seems strange and people living in consensual unions are frequently called "friends" or even just "acquaintances". Their status in society is not clear.

Thus, the respondents mention frequently that marriage gives them the right to "call each other husband and wife" and that it "sanctions their relationship in front of the family". The following quotes stand for good examples:

"I could say that this is my husband, what is important for me, and it changes the social situation somehow. Now, for example when I go to his grandma for Christmas or something, then they call me his acquaintance, they don't even call it right. So it's so annoying that I'm his acquaintance, it's so completely nothing" (Female, in LAT relationship).

"It has changed in the point when I go somewhere I introduce K. as my wife and I can say that. And I don't introduce her as my girl-friend because people look at that less positively. And this is great, and Ifeel better with it" (Male, married after cohabitation). 
The different perception of cohabitation and marriage is reflected also by the system of social norms and directives. Although social pressure for relationship legalization does not seem to be very powerful, we record cases when cohabitation was very difficult because of parents' disapproval or when a partner "moved out a few times, because [he] couldn't stand the pressure" of the family. Noteworthy, this kind of pressure comes dominantly from the parents of a female partner. This is probably related to the fact mentioned in the previous point: marital security appears to be more important for women than for men.

In most cases, however, social pressure is limited to the questions, asked by parents and family, "Are you planning [to marry], or are you not? Do you want to?", and the young couples do not perceive this to be a strong determinant in their choices. Nevertheless, social influence becomes strong and more tangible when it comes to childbearing, which brings us to the fourth point of difference between marriage and cohabitation.

\section{Childbearing}

When a child is born out of wedlock, social control does not only mean that "the neighbors start talking". There are problems at Church, because "the priests say: sorry, first the wedding, then we can talk about baptizing the child". There are everyday troubles for the parents. One respondent gives an example of a colleague, who "couldn't pick up his kid from school. They didn't let him because he is not the 'real' father". Being non-married parents also means that "this child would be somehow stigmatized one day" in school or in the peer group. People also predict legal problems "in case anything happens".

It is clear from the interviews that marriage and parenthood are inseparable. Children are needed to complete the marriage, "Marriage without a child is not a marriage". It is "just a couple with a paper". And marriage is the main condition for having children. One of the respondents says, "We knew that when we want to have a child - then we need to fix a wedding”. Marriage should take place before childbearing in order "not to make this life abnormal". This indicates that giving birth out of wedlock is perceived as something not normal. Again, similar opinions are commonly shared by men and women of different marital status. All in all, marriage is seen as the only approved space for childbearing. This is the last, but substantial difference between formal and informal unions. 


\subsection{Cohabitation - a dead end}

The majority of respondents accept cohabitation, but none of them finds it attractive. The differences mentioned above make the reasons for that clear. The long-term living together without getting married is perceived evidently as a "dead end". Time stands for an important factor here. Premarital cohabitation is perceived in a relatively positive manner, but when a couple cohabits too long, it becomes problematic. One respondent, when talking about premarital cohabitation, explains,

"This is fine - let them try. But let's not treat it that I would be living with her for 5-10 years because it suits me, because I live with her and I don't need to get married. It seems to me that it's a vicious circle in this case" (Male, married directly)

This situation seems to be a "vicious circle" for two main reasons. First, because it indicates that commitment of the partners does not increase. The reoccurring themes of security, binding, responsibility, commitment, marital vows and stability are most striking in the discourse concerning cohabitation and marriage. Secondly, it is not an acceptable space for childbearing.

The interviewees acknowledge the different social status of family, when it is based on marriage. In the rare cases, when they find living in and out of wedlock equal and say that they "do not need this paper", they still want to marry before having children in order to comply with social norms. One of the interviewees says openly,

"I am not an avant-garde type of person and I would like to live according to the rolemodels and expectations" (Female, in LAT relationship).

For the above reasons, cohabitation is always perceived as a temporary arrangement and a step towards marriage. Each relationship concludes in wedlock. Even for the respondents who strongly support cohabitation, marriage means something more; even if sometimes it is difficult for them to explain this. As one of the respondents puts it, "If we were not married I would, of course, still consider us as a loving family, but something would be missing then" (Male, married after cohabitation). 


\section{Summary and discussion}

We set our task to explore the meanings and the attitudes related to cohabitation, and to what extent they are in contrast to those related to marriage in the perception and expressions of young people in Warsaw in the early 2000s. The interest of such exploration is seated in uncovering the cultural context for the ambiguous picture that cohabitation in Poland seems to draw when looking at survey data on attitudes and behavior. On the one hand, a quite diffused approval of cohabitation shows little consistency with the very low rate of cohabiting choices. On the other hand, this particular conjuncture of behavior and attitudes places Poland in a peculiar position in relation to the theoretical discussions which read the diffusion of cohabitation as an innovation diffusion process. Poland does not fit well any of the 4 stages of the diffusion paradigm discussed in section 2.

Our exploration is based on a purposive sample of respondents, selected with the aim of representing the most receptive to modern attitudes and behavior towards cohabitation and innovations in general, that is a sample of medium to highly educated metropolitan young adults. After analyzing meaning, attitudes and experiences of cohabitation we conclude that this form of living arrangement is perceived positively only if it is a premarital arrangement, agreed on either as a test for the marriage or as an interim step in the family formation process. The trial role of cohabitation is commonly recognized and accepted, although there is no consensus as to whether the "probationary period" is useful and desirable. Certainly, the fact that moving in with a partner means spending more time together and the fact that it requires more involvement are both positively evaluated. However, these positive attitudes are referred to the committing and the sharing of time and space with each other and in this sense they concern cohabitation and marriage to the same extent. Sharing a household is more appealing than courtship, without living together, but in this respect a cohabitating union does not seem to have any relative advantages in comparison with a marital union. Also, commitment is key in both kinds of union. It is expected that the loyalty and the dedication of partners towards each other will be increasing with time and that an informal union will develop into the formal one accordingly. If the commitment is not increasing, the couple will separate. Therefore, a cohabiting union leads with no other option to a marital union, in our respondents' perspective. 
The expressed tolerance towards couples who do not marry eventually, should not be interpreted too quickly as a sign of emancipation from an institutionalized life course. Most respondents still find marriage the most desirable for themselves, but they respect personal choices by reducing social pressure. Nevertheless, cohabitation as a life choice lacks social approval and choosing to give birth to a child outside the marriage bond is perceived to some extent as problematic, if not a deviant behavior all together. The respondents find premarital cohabitation attractive to some extent, but wedlock remains the desirable goal and the dreamed couple living arrangement. The desire to marry becomes even stronger when there is a perspective of parenthood. Therefore, it is very important to clearly differentiate between various meanings of cohabitation and also between tolerance toward consensual unions and their favorable evaluation. These distinctions in surveys would allow for capturing better the phenomenon of cohabitation in future.

Shall we conclude that the second stage of cohabitation diffusion, when living together without marrying is perceived as a premarital stage (Prinz 1995), has already started in Poland, at least in the modern, urban setting? Yes, to some extent. Even in this context, some aspects of premarital cohabitation happen to be evaluated ambiguously or even negatively. In other words: the new meanings of cohabitation appear but it is not sure if the ideational shift (van de Kaa, 1987, Lesthaeghe and Surkyn 1988) in Poland is advanced enough to produce a clear change in attitudes. As a result, the new behavior (cohabitation) does not spread rapidly either. The picture of ideational change that one can draw from this conclusion is very compound and consequential. First, a limited liberalization of norms can be observed. It is indicated by a clear approval of premarital sex and cohabitation, and tolerance towards longterm consensual unions. The increasing tolerance for life choices that are not traditional provides some ground for cohabitation diffusion. Still, we need to remember that the norm forbidding extra-marital births remains rigid.

Second, whereas the main features of ideational shift are growing individualism and growing desire for independence (Lesthaeghe, Surkyn, 1988; van de Kaa, 1987, 2001), these trends does not apply to Poland. To our respondents, the highest value is commitment.

It would be easy to argue that the very positive evaluation of marital commitment is a product of the Catholic culture of Poland. However, this causal relation does not necessarily exist in young people's minds, and the influence of the Catholic Church moral recommendations are 
not explicitly recognized. The evaluation of cohabitation as a non desirable alternative to marriage is deeply internalized and it is unlikely that the process of secularization will change it in the short run. The strong internalization of this value is in our opinion the main reason why marriage does not lose its power in Poland.

However, because the young people aim at a stable and happy marriage, they acknowledge the testing role of cohabitation or even find it natural to live together beforehand. The paths of family formation are changing, incorporating the stage of premarital cohabitation. We conclude that this form of cohabitation will become more common, although marriage will remain very strong at the same time.

The consideration of the local culture by investigating the socially constructed meanings of non-marital living together enhances our comprehension of the ambiguous picture of cohabitation diffusion in Poland. The approach we took allows for explaining the coexistence of the strong support for marriage with the approval for living together in an informal union. The study indicates that the shift in attitudes and higher approval of cohabitation is not always caused by growing individualism, as the Second Demographic Transition model would imply. We suggest that the similar situation could have been or still can be observed in other European countries with a strong familistic tradition, for instance in Southern Europe. As behaviors related to marriage and cohabitation, are not at all identical across the continent, certainly, the cultural aspects and locally constructed meaning of various family forms, have to be taken into consideration when trying to explain these differences. 


\section{Acknowledgement}

We would like to thank Susan L. Brown for being an excellent discussant of the previous version of this article at the Annual Meeting of PAA 2006. We also highly appreciate the comments given by Inge Hutter. Finally, we would like to thank Susann Backer and Yvonne Sandor for their extremely valuable language editing.

\section{References:}

Ajzen, I., Fishbein, M. (1980). Understanding Attitudes and Predicting Social Behavior, Upper Saddle River NJ: Prentice-Hall, Inc.

Bachrach, C., Hindin, M. J., Thomson, E. (2000). The changing shape of ties that bind: an overview and synthesis. In: L. Waite, C. Bachrach, M. Mindin, E. Thomson, A. Thornton (Eds.): Ties that Bind: Perspectives on marriage and cohabitation. New York: Aldine de Gruyter.

Caldwell, J.C. (1982). The wealth flow theory of fertility decline. In: C. Hoehn, R. Mackensen (Eds.): Determinants of Fertility Trends: theories re-examined. Liege: Ordina Editions.

Caldwell, J.C. (1985). Strengths and limitations of the survey approach for measuring and understanding fertility change: alternative possibilities. In J. Cleland, J. Hobcraft, B. Dinesen (Eds.): Reproductive Change in Developing Countries: insights from the World Fertility Survey. London [et al.]: Oxford University Press.

Carmichael, G. A. (1995). Consensual partnering in the more developed countries. Journal of Australian Population Association, 12 (1), 51-86.

Charmaz, K. (2000). Grounded theory. Objectivist and constructivist methods. In N.K. Denzin, Y. Lincoln (Eds.): The Handbook of Qualitative Research. Thousand Oaks [et al.]: Sage Publications.

Clarkberg, M., Stolzenberg, R.M., Waite, L.J. (1995). Attitudes, values, and entrance into cohabitation versus marital unions. Social Forces, 74(2): 609-632.

Corijn, M., Manting, D. (2000). The choice of living arrangement after leaving the parental home. In: J. de Beer and F. Deven (eds.) Diversity in Family Formation. Netherlands: Kluwert Academic Publishers. pp. 33-58.

CSO (2003). Central Statistical Office (CSO). National Census 2002. Population. State and demographic-social structure. Warsaw: CSO.

CSO (2005). Central Statistical Office (CSO). Statistical yearbook of the Republic of Poland. Warsaw: CSO. 
Flick, U. (2002). An introduction to Qualitative Research. London, Thousand Oaks, New Delhi: Sage Publications.

Haskey, J. (2001). Demographic aspects of cohabitation in Great Britain. International Journal of Law, Policy and Family, (15), 51-67.

International Social Survey Program (1994). Family and Changing Gender Roles I. Codebook. Koeln: Zentralarchiv fuer empirische Socialforschung.

International Social Survey Program (2002). Family and Changing Gender Roles II. Codebook. Koeln: Zentralarchiv fuer empirische Socialforschung.

Kiernan, K. (2000). European perspectives on union formation. In: L. Waite, C. Bachrach, M. Mindin, E. Thomson, A. Thornton (Eds.): Ties that Bind: perspectives on marriage and cohabitation. New York: Aldine de Gruyter.

Kiernan, K. (2002). Cohabitation in Western Europe: trends, issues and implications In: A. Booth and A. Crouter (Eds.): Just Living Together: implications of cohabitation on families, children and social policy. Lawrence Erlbaum Associates.

Knodel, J. (1997). A case for nonanthropological qualitative methods for demographers. Population and Development Review, 23 (4), 847-853.

Kravdal, O. (1999). Does marriage require a stronger economic underpinning than informal cohabitation? Population studies, 53 (1), 63-80.

Kwak, A. (2005). Rodzina w dobie przemian. Matżeństwo i kohabitacja. (Family in the Age of Change. Marriage and Cohabitation). Warsaw: Żak.

Leridon, H., Villenueve-Gokalp, C. (1989). The new couples: number, characteristics and attitudes. Population: An English Selection, 44(1), 203-235.

Lesthaeghe, R. (1983). A century of demographic and cultural change in Western Europe: An exploration of underlying dimensions. Population and Development Review, 9 (3), 411435.

Lesthaeghe, R. (1995). The second demographic transition in Western countries: an interpretation. In: K.O. Mason and A.M. Jensen (Eds.): Gender and family change in industrialized countries. Oxford, Clarendon Press, pp.17-62.

Lesthaeghe, R, Surkyn, J. (1988). Cultural dynamics and economic theories of fertility change. Population and Development Review, 14 (1), 1-45.

Maines, D. R. (2000). The social construction of meaning. Contemporary Sociology, 29(4): 577-584.

Manting, D. (1996). The changing meaning of cohabitation and marriage. European Sociological Review, 12(1), 53-65. 
Martin, C., Thery, I. (2001). The Pacs and marriage and cohabitation in France. International Journal of Law, Policy and Family, 15, 135-158.

Maxwell, J. (1996). Qualitative research design. An interactive approach. Thousand Oaks, London, New Delhi: Sage Publications.

Milles, M.B, Huberman, A.M. (1994). Qualitative data analysis: an expanded sourcebook. Thousand Oaks, CA [et al.]: Sage Publications.

Nazio, T., Blossfeld, H-P. (2003). The diffusion of cohabitation among young women in West Germany, East Germany and Italy. European Journal of Population, 19, 47-82.

Prinz, C. (1995). Cohabiting, Married or Single. England: Avebury.

Rindfuss, R.R., VandenHeuvel, A. (1990). Cohabitation: a precursor to marriage or an alternative to being single? Population and Development Review, 16(4): 703-726.

Rogers, E.M. 1995. Diffusion of Innovations. Fourth Edition. New York, London, et al.: The Free Press.

Rosina, A. (2004). Family Formation and Fertility in Italy. In: G. Dalla Zuanna and G. A. Micheli (Eds.) Strong Family and Low Fertility: A Paradox? Dordrecht/ Boston/ London: Kluwer Academic Publishers.

Rosina, A., Fraboni, R. (2004). Is marriage losing its centrality in Italy? Demographic Research, 11 (6).

Ryan, G. W., Bernard, H. R. (2000). Data management and analysis methods. In N.K. Denzin, Y. Lincoln (Eds.): The handbook of qualitative research. Thousand Oaks [et al.]: Sage Publications.

Schwandt, T. A. (2000). Three epistemological stances for qualitative inquiry. Interpretivism, hermeneutics, and social constructionism. In N.K. Denzin, Y. Lincoln (Eds.): The handbook of qualitative research. Thousand Oaks [et al.]: Sage Publications.

Slany, K. (2002). Alternatywne formy życia matżeńsko-rodzinnego w ponowoczesnym świecie. (Alternative forms of marital-family settings in the post-modern world). Krakow: Nomos.

Strauss, A., Corbin, J. (1998). Basics of the Qualitative Research. Techniques and procedures for developing grounded theory. Thousand Oaks: Sage Publications.

Surkyn, J., Lesthaeghe, R. 2004. Value orientation and the Second Demographic Transition in Northern, Western and Southern Europe: An update. In: G. Andersson, G. Neyer (Eds.): Contemporary research on European fertility. Demographic Research, Special Collection 3, Article 3. Available from: http://www.demographic-research.org/

Thornton, A. (1989). Changing attitudes toward family issues in the United States. Journal of Marriage and the Family, 51(4): 873-893. 
Thurstone, L. L. (1931). The measurement of social attitudes. Journal of Abnormal Psychology, 26(3): 249-269.

Trost, J. (1978). A renewed social institution: non-marital cohabitation. Acta Sociologica, 21(4): 303-315.

Witzel, Andreas (2000). The problem-centered interview. Forum Qualitative Sozialforschung /Forum: Qualitative Social Research [On-line Journal], 1(1). Available at: http://www.qualitative-research.net/fqs-texte/1-00/1-00witzel-e.htm.

Van de Kaa (1987). Europe's Second Demographic Transition. Population Bulletin, 42 (1), 159.

Van de Kaa (2001). Postmodern fertility preferences: from changing value orientation to new behavior. Population and Development Review, 27, Supplement: Global Fertility Transition, 290-331.

Villeneuve-Gokalp, C. (1991). From marriage to informal union: recent changes in the behaviour of French couples. Population: An English Selection, 3, 81-111. 


\section{Appendix 1}

Sample structure

Number of respondents by gender, marital status, parity, and education.

\begin{tabular}{|c|c|c|c|c|c|c|c|c|}
\hline & & Parity 0 & & & & & otal & Total \\
\hline $\begin{array}{c}\text { Educ. } \\
\text { level }\end{array}$ & $\begin{array}{c}\text { Single/ } \\
\text { LAT }\end{array}$ & Cohab. & Married & Cohab. & Married & Fem & Male & \\
\hline Lower & $\begin{array}{c}3 \\
1 \mathrm{~F} / 2 \mathrm{M}\end{array}$ & $\begin{array}{c}3 \\
2 \mathrm{~F} / 1 \mathrm{M}\end{array}$ & $\begin{array}{c}4 \\
1 \mathrm{~F} / 3 \mathrm{M}\end{array}$ & $\begin{array}{c}3 \\
1 \mathrm{~F} / 2 \mathrm{M}\end{array}$ & $\begin{array}{c}7 \\
3 \mathrm{~F} / 4 \mathrm{M}\end{array}$ & 8 & 12 & 20 \\
\hline Higher & $\begin{array}{c}8 \\
6 \mathrm{~F} / 2 \mathrm{M}\end{array}$ & $\begin{array}{c}4 \\
2 \mathrm{~F} / 2 \mathrm{M}\end{array}$ & $\begin{array}{c}12 \\
7 \mathrm{~F} / 5 \mathrm{M}\end{array}$ & $\begin{array}{c}1 \\
1 \mathrm{~F}\end{array}$ & $\begin{array}{c}3 \\
1 \mathrm{~F} / 2 \mathrm{M}\end{array}$ & 17 & 11 & 28 \\
\hline Fem & 7 & 4 & 8 & 2 & 4 & \multirow{3}{*}{\multicolumn{3}{|c|}{$\begin{array}{c}\text { Total number of } \\
\text { interviews } n=48\end{array}$}} \\
\hline Male & 4 & 3 & 8 & 2 & 6 & & & \\
\hline Total & 11 & 7 & 16 & 4 & 10 & & & \\
\hline
\end{tabular}

